\title{
PULL-OUT RESPONSE OF SINGLE STEEL FIBER EMBEDDED IN PVA FIBER REINFORCED CEMENTITIOUS MATRIX
}

\author{
JING YU*, LINGSHI MENG ${ }^{\dagger}$ AND CHRISTOPHER K. Y. LEUNG ${ }^{\dagger \dagger}$ \\ *Hong Kong University of Science and Technology \\ Hong Kong, China \\ e-mail: jyuad@connect.ust.hk \\ ${ }^{\dagger}$ Hong Kong University of Science and Technology \\ Hong Kong, China \\ e-mail:1meng@ust.hk \\ ${ }^{\dagger}$ Hong Kong University of Science and Technology \\ Hong Kong, China \\ e-mail: ckleung@ust.hk
}

Key words: SHCC, Hybrid Fiber, Synergistic Effect, Inclined Fiber, Debonding and Pulling-out

\begin{abstract}
Comparing to Strain Hardening Cementitious Composites (SHCC) with polyvinyl alcohol (PVA) fibers alone, recent test results show that the hybridization of PVA and steel fibers can improve the crack control ability and shear performance of SHCC, indicating a possible synergistic effect between the two kinds of fibers. The objective of this paper is to investigate the physical basis behind the synergy between PVA and steel fibers. As steel fibers are much larger in diameter than the PVA fibers, one can consider them to be embedded inside a PVA fiber reinforced matrix. With a specially designed testing set-up, fiber pull-out test is performed on a single steel fiber embedded inside a cementitious block with different contents of PVA fibers. In the test, the load verses displacement relationship during fiber debonding and pull-out is measured. The parameters investigated include the geometry of steel fibers, the fiber inclination angle $\left(0^{\circ}, 30^{\circ}\right.$ and $\left.60^{\circ}\right)$, as well as the PVA fiber volume fraction $(0 \%$ as control, $1.0 \%$ and $2.0 \%)$. With the test results, it is possible to quantify the synergistic effect between PVA and steel fibers, which can be used for the optimal design of hybrid $\mathrm{PVA} /$ steel fiber SHCC in the future.
\end{abstract}

\section{INTRODUCTION}

Conventional cementitious materials are highly brittle. Research on fracture of composites has led to the development of Strain-Hardening Cementitious Composites (SHCC) exhibiting tensile strain hardening and multiple cracking [1-3]. With tremendous ductility, excellent crack control ability, high toughness, as well as good energy absorption,
SHCC is an attractive material for many structural applications [4]. In common SHCC, only polymeric fibers such as polyethylene (PE) or polyvinyl alcohol (PVA) have been employed, as high ductility can be achieved with a relative low fiber volume fraction (about $2 \%$ ). To further enhance the performance of SHCC, the use of hybrid fibers has been investigated [5-9]. Comparing to SHCC with PVA fibers alone, recent test results show that the hybridization of PVA and steel fibers can 
improve the crack control ability and shear performance of SHCC [10], indicating a possible synergistic effect between the two kinds of fibers.

The pull-out of a single fiber embedded in cementitious matrix is widely recognized as one of the basic tests to be performed to provide information on the expected behavior of a given fiber reinforced cementitious composites, for straight fibers [11-14] as well as deformed fibers [15-19]. Fiber/matrix debonding and frictional sliding are the two main mechanisms controlling the pull-out response of straight fibers, while additional anchor mechanism should be considered for deformed fibers. Thus, it is of great importance that the pull-out test be interpreted in a way that yields the true material parameters governing the physical process.

In most short fiber reinforced cementitious composites, fibers are randomly distributed. Generally speaking, the bridging force provided by an inclined fiber (i.e., a fiber which is not perpendicular to the crack) can be considered as the vector sum of two components (Fig. 1): a debonding/pull-out component along the axis of the fiber and a bending component perpendicular to the fiber direction. For an inclined flexible fiber (such as PVA fibers in the present study), it was considered as a flexible string passing over a frictional pulley, and a snubbing friction model was derived to relate the peak pull-out load to the fiber inclination angle by $\mathrm{Li}$ et al. [20]. The model was further evaluated and modified by Maalej et al. [21] and Leung and Ybanez [12]. On the other hand, for an inclined stiff fiber (such as steel fibers in the present study), Leung and Chi [22] developed a micromechanical model focusing on the component of crackbridging force due to fiber bending, which is obtained by analyzing the bending of an elastoplastic beam on an elastic foundation with variable stiffness along the fiber. The model was further improved by Fantilli and Vallini [23]. In addition, some new models for inclined deformed fibers have also been developed [24, 25].

Pull-out tests with inclined steel fibers have been reported by various investigators [26-29].
However, the available results are somewhat inconsistent. In some cases there exists an optimum inclination angle with respect to the maximum fiber pull-out load, but other tests shows the maximum pull-out load decreases with increasing inclination angle.
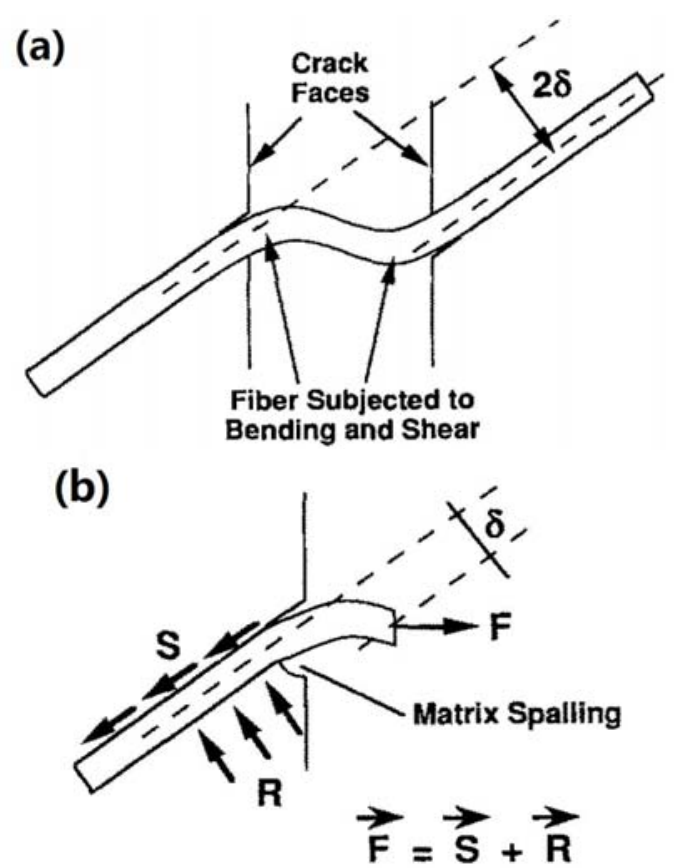

Figure 1: (a) Bending and shearing of fiber across a crack, (b) Components of a crack-bridging force ([30]).

\section{RESEARCH OBJECTIVE}

The objective of this paper is to investigate the physical basis behind the synergy between PVA and steel fibers in SHCC. As steel fibers are much larger in diameter than the PVA fibers, one can consider them to be embedded inside a PVA fiber reinforced matrix. It is speculated that the PVA fibers can reinforce the matrix, hence decreasing the matrix spalling caused by steel fibers and increasing the pullout resistance. Both aligned and inclined single steel fiber pulling-out from PVA fiber reinforced matrix are experimentally studied, based on a specially designed single-steel-fiber pullout test set-up developed by Leung and coworkers $[12,31]$. The parameters investigated include the geometry of steel fibers, the fiber inclination angle $\left(0^{\circ}, 30^{\circ}\right.$ and $\left.60^{\circ}\right)$, as well as the PVA fiber volume fraction $(0 \%$ as control, $1.0 \%$ and $2.0 \%$ ). With the test results, it is possible to quantify the synergistic effect 
between PVA and steel fibers, which will be used for the optimal design of hybrid PVA/steel fiber SHCC in the future.

\section{EXPERIMENTAL PROGRAM}

\subsection{Materials}

A matrix with ultra-high volume fly ash (fly ash-to-binder ratio of $80 \%$ by weight) designed by the authors [32], with mix proportions shown in Table 1, was employed. The matrix can achieve a compressive strength of more than $40 \mathrm{MPa}$ in 7-day age and more than 55 $\mathrm{MPa}$ in 28-day age. The Type I 52.5N Portland cement was produced by Green Island Cement Co., Ltd. and the Class F fly ash was provided by China Power and Light Co., Ltd. The silica fume was marketed as Elkem Microsilica $920 \mathrm{U}$, with the bulk density of 200 to 350 $\mathrm{kg} / \mathrm{m}^{3}$. Silica sand with a specific gravity of 2.61 and particle sizes ranging from 120 to 212 $\mu \mathrm{m}$ was used. A very small amount of AVDA 105 super-plasticizer (SP), with solid content of $30 \%$, produced by Grace Construction Products Co., Ltd. was added to adjust the rheological properties of the fresh mix for better fiber distribution and workability. The nominal physical properties of the fibers are given in Table 2, for Kuraray K-II REC15 PVA fiber, Dramix ZP305 steel fiber and Dramix RC80/60-BM steel fiber. Both Dramix fibers are made with hooks at the fiber end. In the pullout tests on straight fiber, the hooks are cut.

Table 1: Mix proportion of the matrix (by weight)

\begin{tabular}{ccccc}
\hline Cement & Fly Ash & Silica Fume & Sand & Water \\
\hline 0.18 & 0.8 & 0.02 & 0.2 & 0.2 \\
\hline
\end{tabular}

Table 2: Properties of fibers

\begin{tabular}{ccccccc}
\hline Fiber Types & $\begin{array}{c}\text { Length } \\
(\mathrm{mm})\end{array}$ & $\begin{array}{c}\text { Diameter } \\
(\mathrm{mm})\end{array}$ & $\begin{array}{c}\text { Length of } \\
\text { One Hook } \\
(\mathrm{mm})\end{array}$ & $\begin{array}{c}\text { Modulus of } \\
\text { Elasticity (Gpa) }\end{array}$ & $\begin{array}{c}\text { Strength } \\
(\mathrm{Mpa})\end{array}$ & Surface Coating \\
\hline PVA & 8 & 0.039 & - & 40 & 1600 & Oil (1.2\% by weight) \\
ZP305 & 30 & 0.55 & 4 & 210 & 1345 & None \\
RC-80/60-BM & 60 & 0.75 & 5 & 210 & 1550 & None \\
\hline
\end{tabular}

(a)

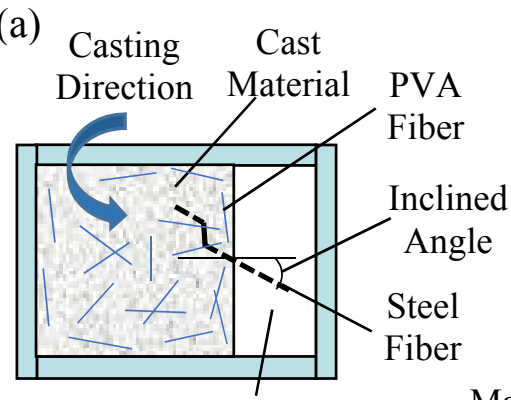

Plastic Block with Drilled

Hole at Specified Angle to Hold Fiber (b) A Screw that can be

Tightened to Hold the Fiber in Place

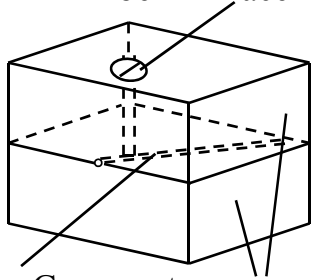

Matching Groove at Required Angle for fiber to reside
Top and

Bottom Parts

Connected by (c)

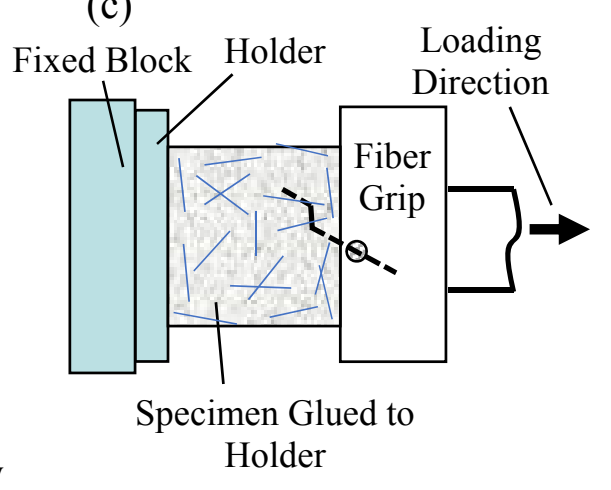

Figure 2: (a) Casting of specimen; (b) Details of the fiber grip; (c) Set-up for pull-out test.

\subsection{Sample preparation}

For each group listed in Table 3, at least 6 samples with one inclined angle have been prepared, and at least 3 useful curves have been recorded.

The steel fiber was first inserted into a small plexiglass block with a hole drilled at the appropriate angle in the middle (Fig. 2(a)). A fiber length of $8 \mathrm{~mm}$ was left outside the block. The hole in the block was made slightly larger than the fiber size, and molding clay was placed in the hole to secure the fiber. After the fibers are secured in the blocks, the blocks were placed in a matching steel mold. With each mold, one specimen at each designated inclination angle 
$\left(0^{\circ}, 30^{\circ}\right.$ and $\left.60^{\circ}\right)$ could be prepared. The pullout specimen would have the size of $25.4 \mathrm{~mm}$ (length) $\times 25.4 \mathrm{~mm}$ (width) $\times 9.5 \mathrm{~mm}$ (height). Demolding oil was applied to all surfaces that would be in contact with mortar. Extra care was taken to avoid contaminating the fiber surface.

$0 \%, 1.0 \%$ and $2.0 \%$ of PVA fibers by volume were introduced into the matrix by wet mixing. To cast specimens, materials was mixed by hand with an eggbeater and added slowly into the mold in two layers, to achieve a 2D PVA fiber distribution in the samples. Compaction is achieved by tapping the matrix with a small steel stick. After finishing the surface, the specimens were covered with a polyethylene sheet to prevent loss of moisture and stored for 24 hours at room temperature prior to demolding. The demolded specimens were cured in the fog room at the temperature of $23^{\circ} \mathrm{C} \pm 2^{\circ} \mathrm{C}$ and the relative humidity of $95 \% \pm 5 \%$ until they reached 7 -day age [33].

Table 3: Experimental Program

\begin{tabular}{|c|c|c|c|}
\hline $\begin{array}{l}\text { Group } \\
\text { ID }\end{array}$ & $\begin{array}{l}\text { Steel Fiber } \\
\text { Geometry }\end{array}$ & $\begin{array}{c}\text { Steel Fiber } \\
\text { Incline } \\
\text { Angle }\end{array}$ & $\begin{array}{c}\text { PVA } \\
\text { Volume } \\
\text { Fraction }\end{array}$ \\
\hline O6 & $\begin{array}{l}0.55 \mathrm{~mm} w / \mathrm{o} \\
\text { hook }\end{array}$ & $0^{\circ}, 30^{\circ}, 60^{\circ}$ & $0.0 \%$ \\
\hline O8 & $\begin{array}{c}0.55 \mathrm{~mm} \text { w/o } \\
\text { hook }\end{array}$ & $0^{\circ}, 30^{\circ}, 60^{\circ}$ & $1.0 \%$ \\
\hline $\mathrm{O} 10$ & $\begin{array}{c}0.55 \mathrm{~mm} \text { w/o } \\
\text { hook }\end{array}$ & $0^{\circ}, 30^{\circ}, 60^{\circ}$ & $2.0 \%$ \\
\hline $\mathrm{O} 11$ & $\begin{array}{l}0.55 \mathrm{~mm} \text { w/ } \\
\text { hook }\end{array}$ & $0^{\circ}, 30^{\circ}, 60^{\circ}$ & $0.0 \%$ \\
\hline $\mathrm{O} 13$ & $\begin{array}{c}0.55 \mathrm{~mm} \mathrm{w} / \\
\text { hook }\end{array}$ & $0^{\circ}, 30^{\circ}, 60^{\circ}$ & $1.0 \%$ \\
\hline $\mathrm{O} 15$ & $\begin{array}{c}0.55 \mathrm{~mm} \mathrm{w} / \\
\text { hook }\end{array}$ & $0^{\circ}, 30^{\circ}, 60^{\circ}$ & $2.0 \%$ \\
\hline $\mathrm{O} 16$ & $\begin{array}{c}0.75 \mathrm{~mm} \mathrm{w} / \\
\text { hook }\end{array}$ & $0^{\circ}$ & $0.0 \%$ \\
\hline $\mathrm{O} 18$ & $\begin{array}{c}0.75 \mathrm{~mm} \mathrm{w} / \\
\text { hook }\end{array}$ & $0^{\circ}$ & $1.0 \%$ \\
\hline $\mathrm{O} 20$ & $\begin{array}{c}0.75 \mathrm{~mm} \mathrm{w} / \\
\text { hook }\end{array}$ & $0^{\circ}$ & $2.0 \%$ \\
\hline
\end{tabular}

\subsection{Test setup and testing procedure}

To carry out fiber pull-out tests, special grips are designed to hold the fiber (Fig. 2(b)). The grip consists of two separate parts connected by screws. At the middle of the grip there is a hole drilled at the required angle. The hole size is made as close to the fiber size as possible. After inserting the fiber, a screw on top of the hole is tightened to secure the fiber. By using the appropriate grip for a given angle of inclination, it can be ensured that the fibers are straight at the beginning of the test (Fig. 2(c)). After inserting and tightening the steel fiber into the grip, the other side of the pull-out specimen is then glued to a specimen holder. The details of the pull-out apparatus can be found in Leung and Geng [31]. After the specimen is properly placed in the apparatus, a LVDT is placed between the grip and the specimen holder for displacement measurement. The loading rate was fixed at $0.25 \mathrm{~mm} / \mathrm{min}$ under displacement control. The load verses displacement relationship during fiber debonding and pull-out was recorded.

\section{RESULTS AND DISCUSSIONS}

All the fiber pull-out load verses pull-out displacement curves are summarized and shown in Fig. 3 to Fig. 9, while the peak pull-out load and pull-out work verses inclined angle for various PVA fiber content are exhibited in Fig. 10 to Fig. 12. The pull-out work represents energy absorption during the pull-out process.

\subsection{Steel fiber geometry}

Based on the results shown in Fig. 10(a) and Fig. 11(a), the peak pull-out load can be significantly improved by the introduction of a hook at the end of a fiber, but the samples fail with a more brittle manner as shown in the pullout curves.

Comparing Fig. 11(a) and Fig. 12(a), the peak load value is not proportional to the diameter of steel fibers. In addition, as shown in Fig. 6(a) and Fig. 9(a), without PVA fibers, samples with larger steel fibers are more ductile than that with smaller fibers. The possible reason is that in the case with a larger steel fiber, the matrix between the front of the hook and the specimen surface (the shaded region in Fig. 13) fails first due to the larger local force introduced by the fiber, before the fiber is totally pulled out from the matrix. The pull-out displacement is hence larger. 

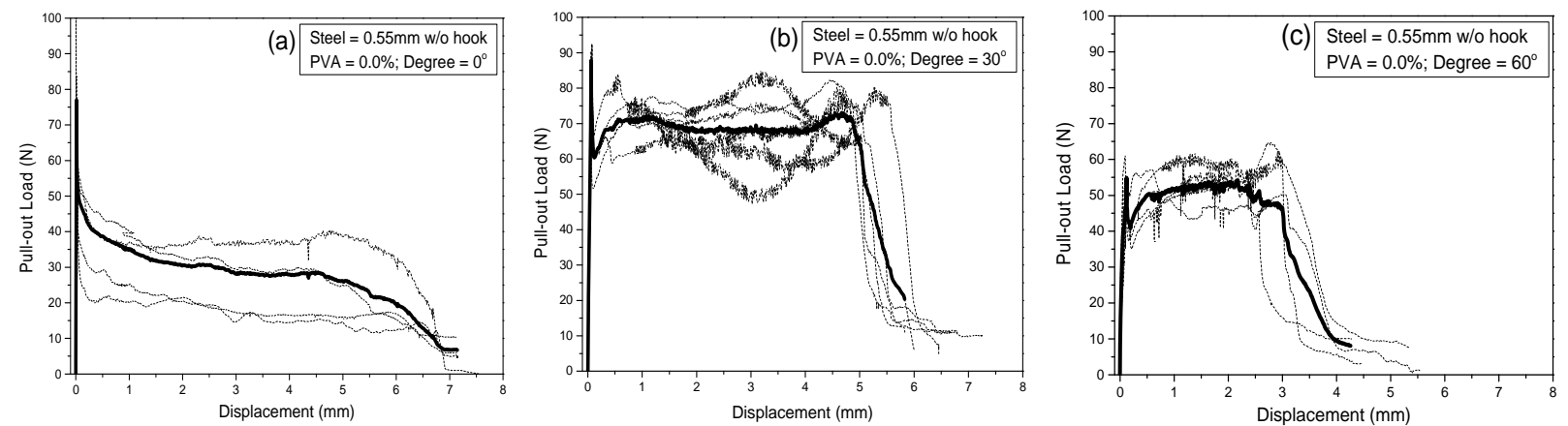

Figure 3: Pull-out response of Group O6: (a) Degree $=0^{0}$; (b) Degree $=30^{\circ}$; (c) Degree $=60^{\circ}$.
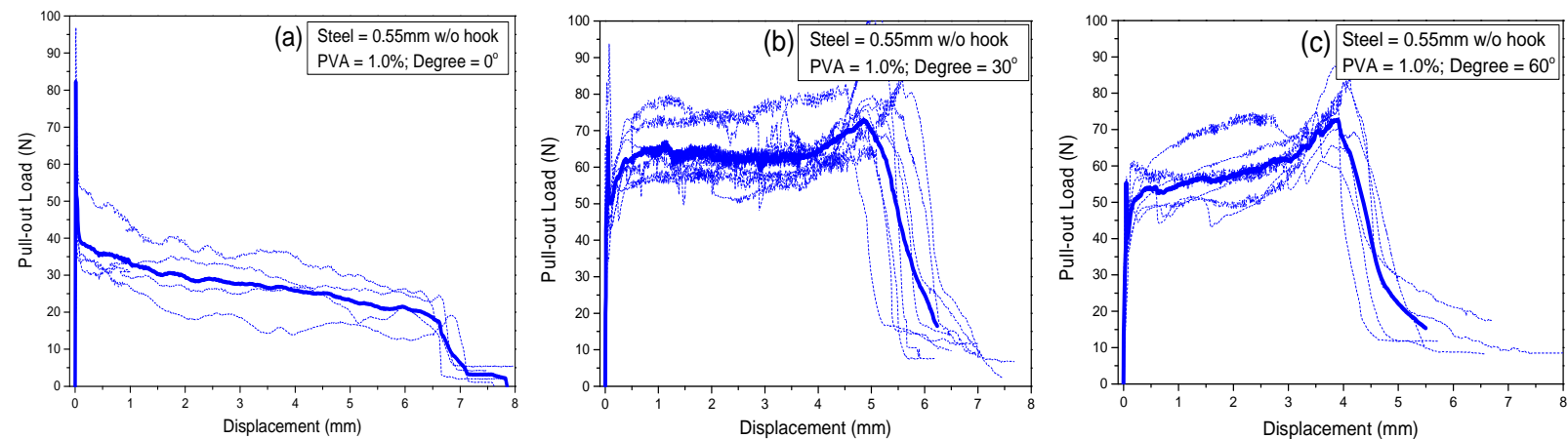

Figure 4: Pull-out response of Group O8: (a) Degree $=0^{0}$; (b) Degree $=30^{\circ}$; (c) Degree $=60^{\circ}$.
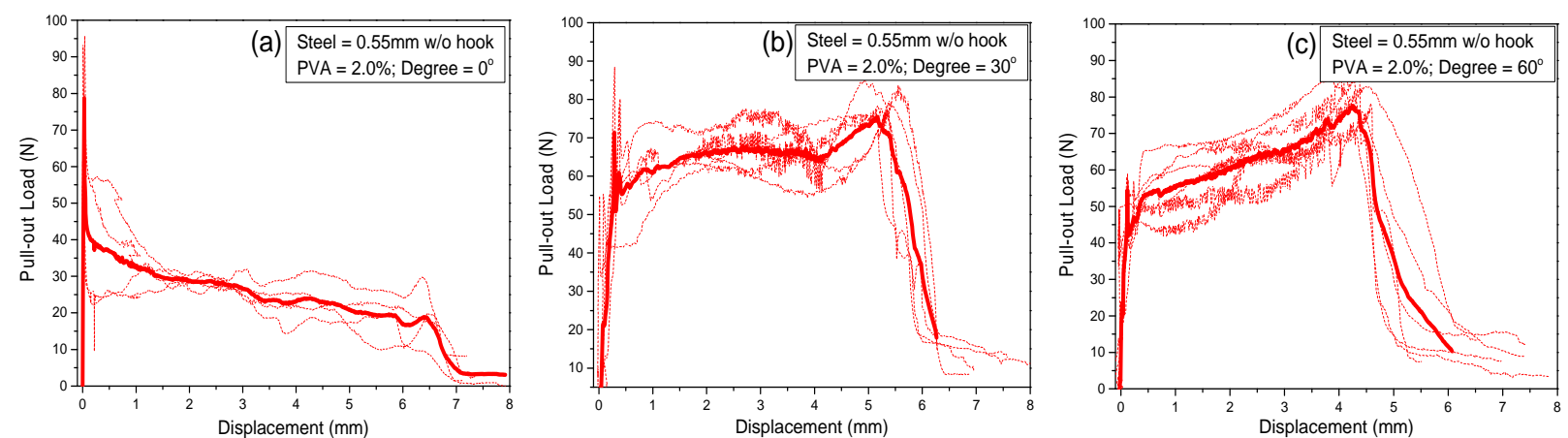

Figure 5: Pull-out response of Group O10: (a) Degree $=0^{0}$; (b) Degree $=30^{\circ}$; (c) Degree $=60^{\circ}$. 

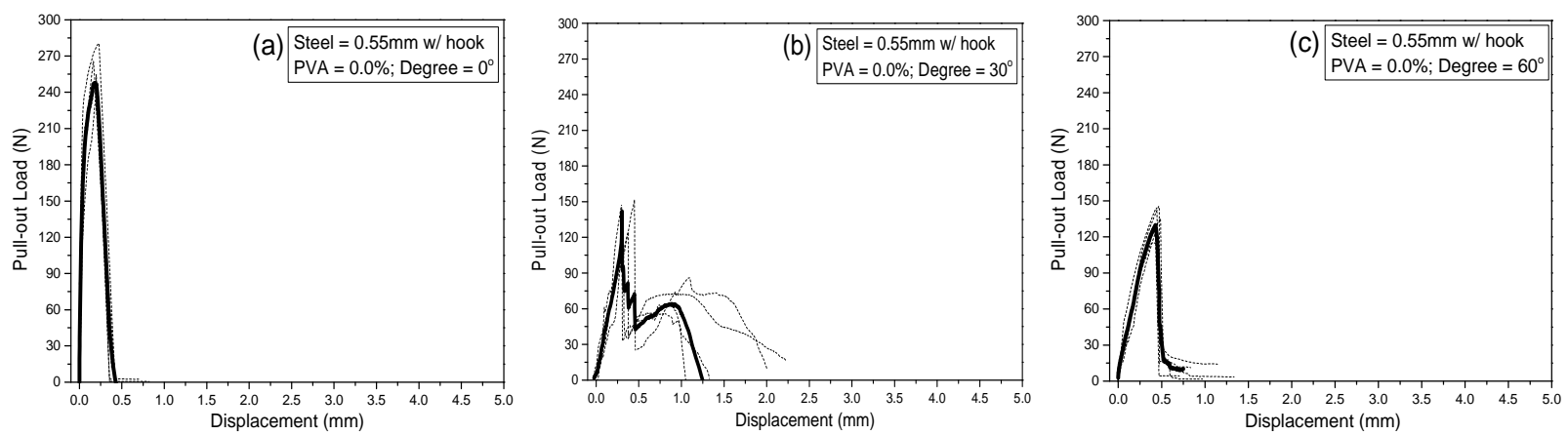

Figure 6: Pull-out response of Group O11: (a) Degree $=0^{0}$; (b) Degree $=30^{\circ}$; (c) Degree $=60^{\circ}$.
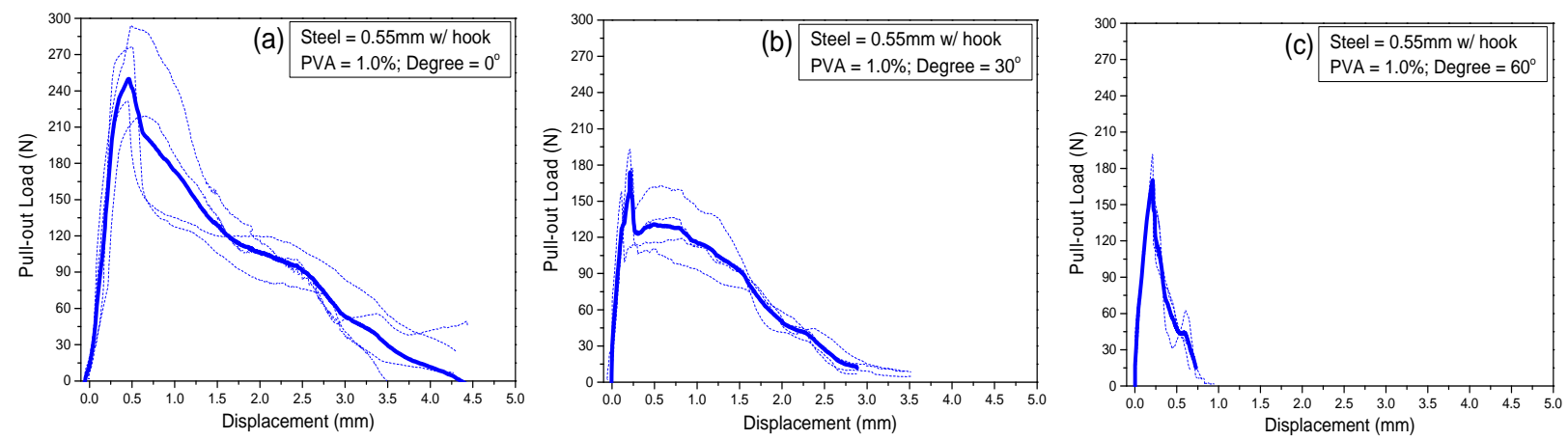

Figure 7: Pull-out response of Group O13: (a) Degree $=0^{\circ}$; (b) Degree $=30^{\circ}$; (c) Degree $=60^{\circ}$.
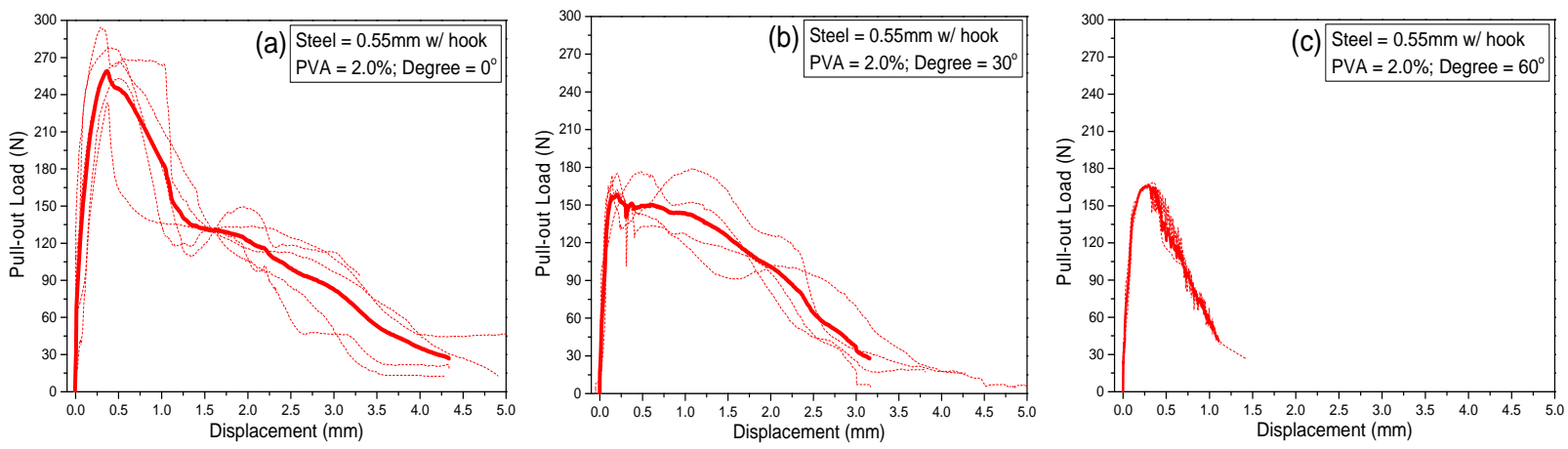

Figure 8: Pull-out response of Group O15: (a) Degree $=0^{0}$; (b) Degree $=30^{\circ}$; (c) Degree $=60^{\circ}$.
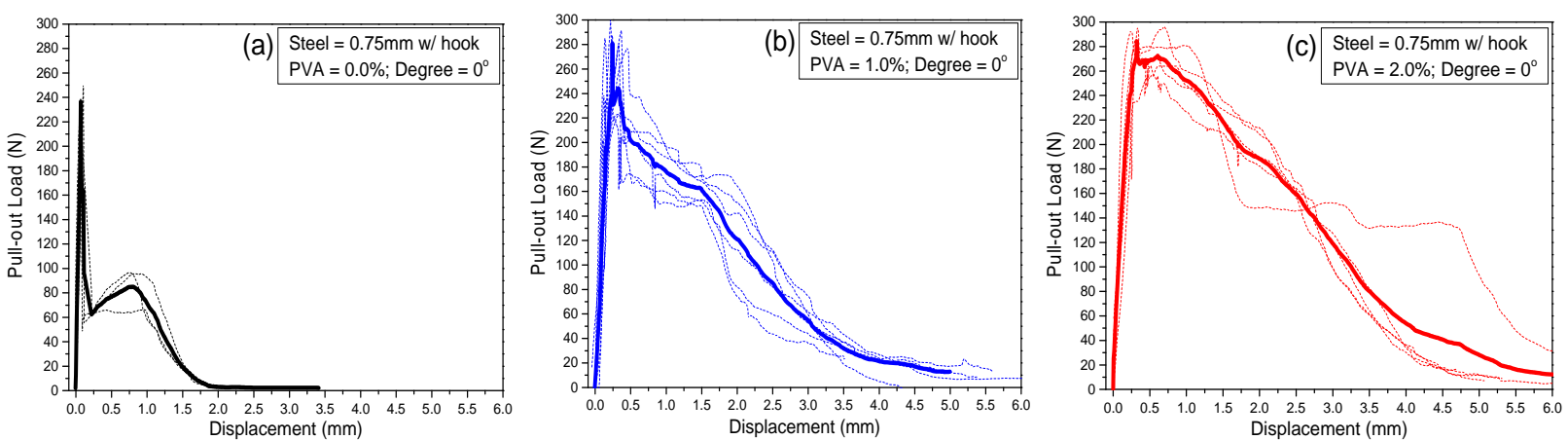

Figure 9: Pull-out response of: (a) Group O16; (b) Group O18; (c) Group O20. 

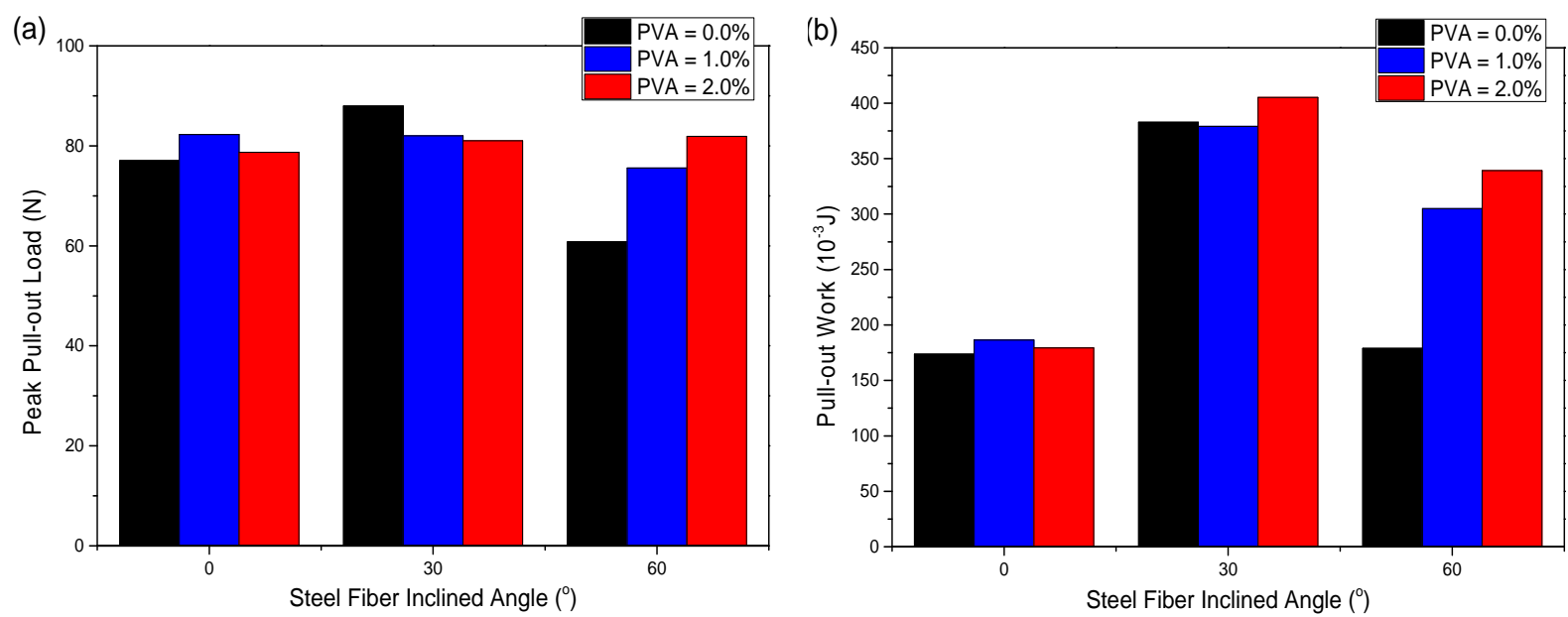

Figure 10: Straight steel fibers $\left(d_{\mathrm{f}}=0.55 \mathrm{~mm}\right)$ : (a) Peak pull-out load; (b) Pull-out work.
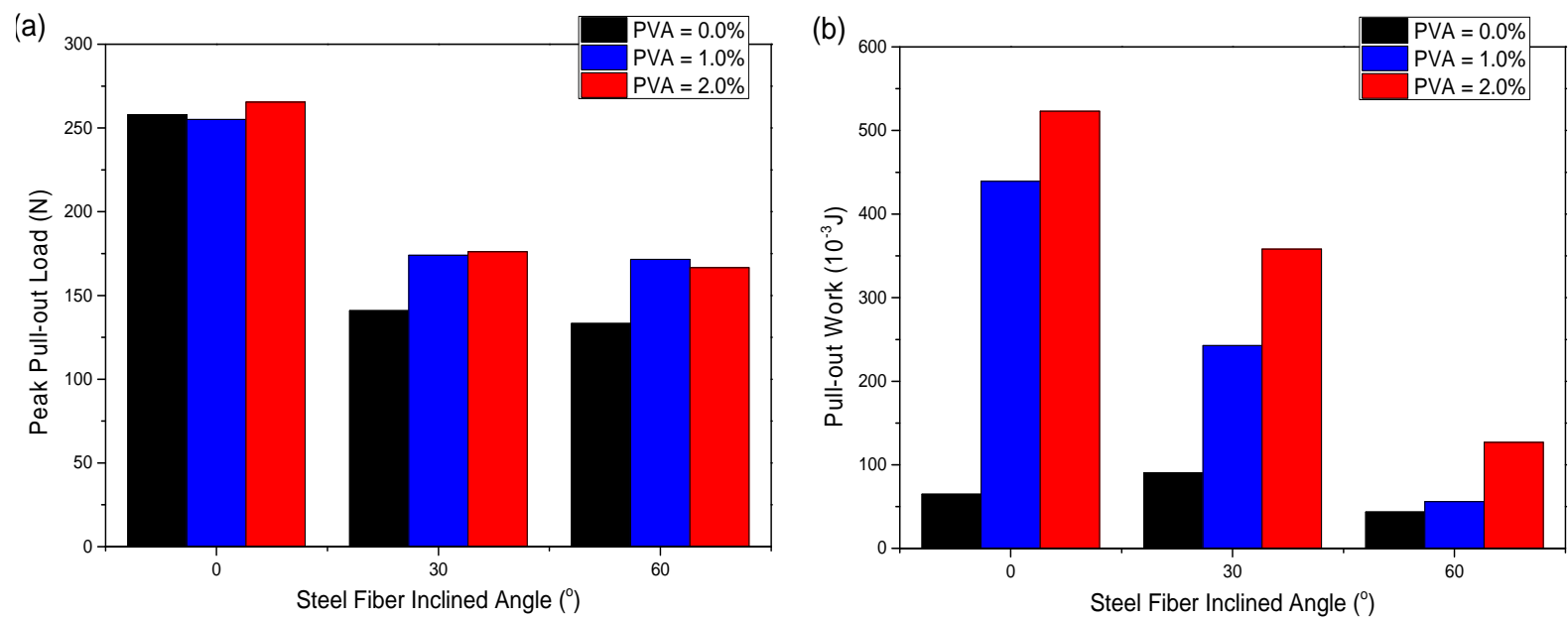

Figure 11: Hooked-end steel fibers $\left(\mathrm{d}_{\mathrm{f}}=0.55 \mathrm{~mm}\right)$ : (a) Peak pull-out load; (b) Pull-out work.
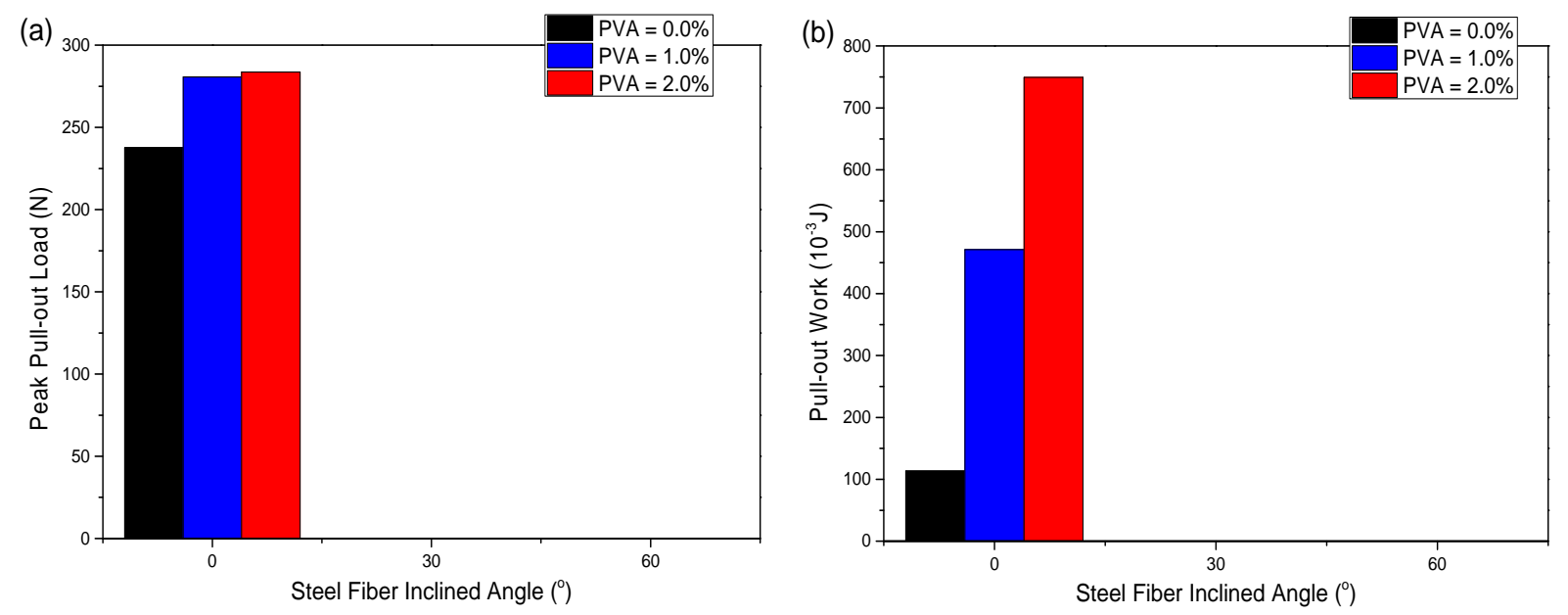

Figure 12: Hooked-end steel fibers $\left(\mathrm{d}_{\mathrm{f}}=0.75 \mathrm{~mm}\right)$ : (a) Peak pull-out load; (b) Pull-out work. 


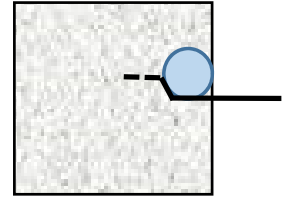

Figure 13: Large local force caused by the hook.

\subsection{Steel fiber inclined angle}

From the results in Fig. 10 for straight fibers, it can be found that the influence of the fiber inclined angle on the peak pull-out load is not significant, especially for those with PVA fibers in the matrix. The inclination of the steel fibers changes the failure mode from a brittle to a more ductile manner, and the samples with $30^{\circ}$ inclined fibers consume more energy than the other cases. Typical failure modes around the pulled out fiber for samples with no PVA fibers and 2.0 vol.\% of PVA fibers are shown in Fig. 14. With PVA fibers in the matrix, the spalling around the steel fiber is significantly reduced.

After complete pull-out, the residual deformations of straight steel fibers embedded in the matrix with 1.0 vol.\% PVA fibers, are shown in Fig. 15. For inclined fibers, the pullout force includes both the debonding component (given by the pull-out curve of the aligned fiber) and the bending component (Fig. 1). Larger residual deformation, which is caused by larger fiber bending component of crackbridging force, can be observed in the case with higher inclined angle.
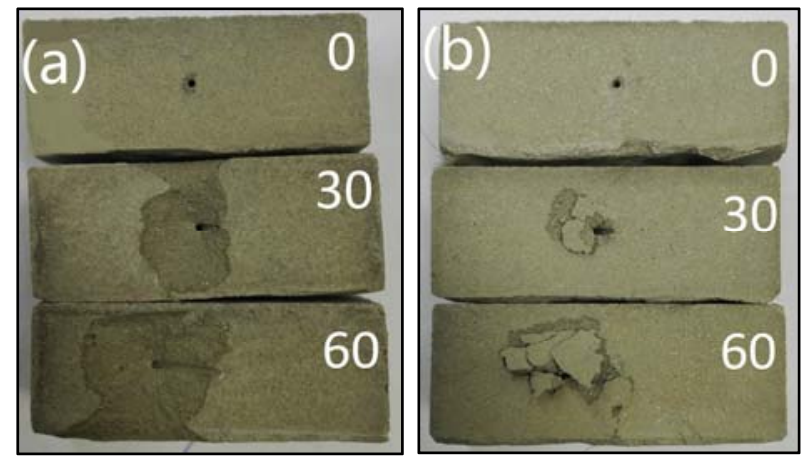

Figure 14: Typical failure modes of (a) O6; (b) O10.
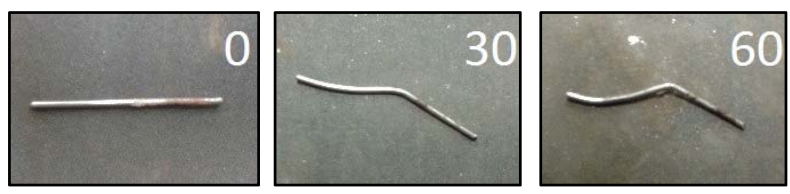

Figure 15: Aligned and inclined straight steel fibers after totally been pulled out (with 1.0 vol.\% PVA).
As indicated in Fig. 11, for the peak pull-out load of hooked-end fibers, the aligned-fiber cases exhibit the highest value, while the samples with $30^{\circ}$ and $60^{\circ}$ inclined fibers shows similar and lower values. It can be observed that the samples fail in a more brittle manner when the fiber angle increases. Typical failure modes of samples around the pulled out fiber without PVA fibers and 1.0 vol.\% PVA fibers are shown in Fig. 16.
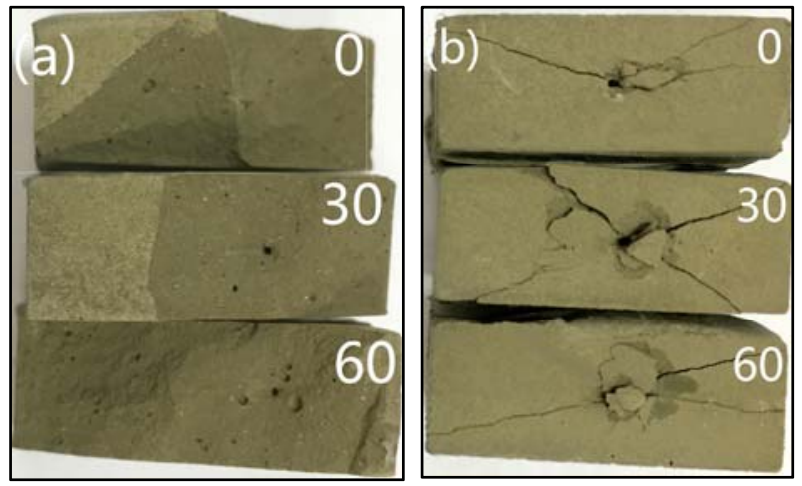

Figure 16: Typical failure modes of (a) $\mathrm{O} 11$; (b) $\mathrm{O} 13$.

\subsection{PVA fiber content}

For the straight steel fiber, the influence of the PVA fiber content is found to vary with different steel fiber inclination angles (Fig. 10). For the cases with aligned fibers, the peak pullout load and the pull-out work are almost the same, which is reasonable since the introduction of PVA fibers may not have significant influence of the fiber/matrix interface for steel fibers.

As shown in Fig. 14, the introduction of fibers into the matrix can reduce matrix spalling around the inclined steel fiber. As a result, the bending component of the pull-out force is increased. For the samples with $30^{\circ}$ inclined fibers, the increase in bending component can compensates for the reduced debonding component. For the speciments with $60^{\circ}$ inclined fibers, the reduced spalling with fiber addition over-compensates for the smaller debonding component, so the pull-out behavior, in terms of the peak pull-out load and the pullout work, are both improved.

Close examination of the present test method reveals one shortcoming. Due to the wall effect [34] introduced by the plexiglass block around 
the steel fiber pull-out region (Fig. 2(a)), the distribution of PVA fibers are restricted, which vary from the real situation in a crack. Modification of the test method has been developed and new tests will be performed.

For the hooked-end steel fibers (Fig. 11 and Fig. 12), the existence of PVA fibers can effectively prevent the matrix spalling and make the samples fail in a more ductile manner, while slightly increasing the peak pull-out load. Typical failure modes at the pull-out point of samples with large hooked-end steel fibers (Group O16, O18 and O20) are shown in Fig. 17. In all cases, spalling is very severe. The control of matrix spalling by PVA fibers can effectively enhance the post-peak behavior in the pull-out curves. The pull-out work is hence significantly increased.

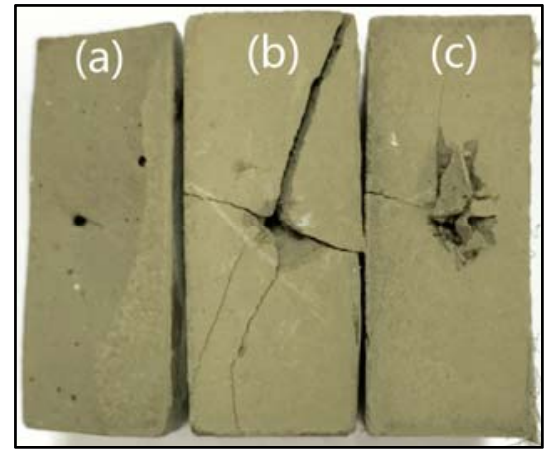

Figure 17: Typical failure modes of (a) O16; (b) O18; (c) $\mathrm{O} 20$

\section{CONCLUSIONS}

With a specially designed testing set-up, fiber pull-out test is performed on a single steel fiber embedded inside a cementitious block with different contents of PVA fibers. The parameters investigated include the geometry of steel fibers, the fiber inclination angle $\left(0^{\circ}, 30^{\circ}\right.$ and $60^{\circ}$ ), as well as the PVA fiber volume fraction ( $0 \%$ as control, $1.0 \%$ and $2.0 \%)$. From the test results, the following conclusions can be made:

1) The peak pull-out load can be significantly improved by the introduction of a hook at the end of a fiber, but the samples fail in a more brittle manner.

2) For the samples with straight steel fibers, the influence of the fiber inclined angle on the peak pull-out load is not significant, especially for those with PVA fibers in the matrix. The inclination of the steel fiber changes the failure mode from a brittle to a more ductile manner, and the samples with $30^{\circ}$ inclined fibers consume more energy than the other cases.

3) The samples with hooked-end steel fibers fail in a more brittle manner with a lower peak pull-out load when the fiber inclined angle increases.

4) The introduction of PVA fibers can effectively prevent the matrix spalling around hooked-end fibers or inclined steel fibers. The samples then fail in a more ductile way. The peak pull-out load may stay similar, but the pull-out work can be significantly increased.

\section{ACKNOWLEDGMENT}

The financial support by the Hong Kong Research Grant Council (GRF 615411), are gratefully acknowledged. The authors would also express their appreciation to Dr. Lik Lam for providing the Dramix RC-80/60-BM steel fibers.

\section{REFERENCES}

[1] V.C. Li, C.K.Y. Leung. 1992. Steady-state and multiple cracking of short random fiber composites. Journal of Engineering Mechanics 118: 2246-2264.

[2] V.C. Li, H.C. Wu. 1992. Conditions for pseudo strain-hardening in fiber reinforced brittle matrix composites. Journal of Applied Mechanics Reviews 45: 390-398.

[3] V.C. Li. 1993. From micromechanics to structural engineering - the design of cementitous composites for civil engineering applications. Journal of Structural Mechanics and Earthquake Engineering 10: 37-48.

[4] V.C. Li. 2008. Engineered Cementitious Composites (ECC) - material, structural, and durability performance. in: E. Nawy (Ed.) Concrete Construction Engineering 
Handbook, CRC Press, 2008.

[5] S.F.U. Ahmed, M. Maalej, P. Paramasivam. 2007. Flexural responses of hybrid steelpolyethylene fiber reinforced cement composites containing high volume fly ash. Construction and Building Materials 21: 1088-1097.

[6] S.F.U. Ahmed, M. Maalej. 2009. Tensile strain hardening behaviour of hybrid steelpolyethylene fibre reinforced cementitious composites. Construction and Building Materials 23: 96-106.

[7] Z. Wang, J. Zhang, J. Wang, Z. Shi. 2014. Tensile performance of polyvinyl alcoholsteel hybrid fiber reinforced cementitious composite with impact of water to binder ratio. Journal of Composite Materials 0: 118.

[8] M. Maalej, S.T. Quek, J. Zhang. 2005. Behavior of hybrid-fiber engineered cementitious composites subjected to dynamic tensile loading and projectile impact. Journal of Materials in Civil Engineering 17: 143-152.

[9] K.T. Soe, Y.X. Zhang, L.C. Zhang. 2013. Impact resistance of hybrid-fiber engineered cementitious composite panels. Composite Structures 104: 320-330.

[10] J. Yu, C.K.Y. Leung, C. Lu. 2015. Tension and shear behavior of hybrid-fiber pseudoductile cementitious composites (PDCC). in: A.M. Brandt, et al. (Eds.) Proceedings of 11th International Symposium on Brittle Matrix Composites (BMC-11) Warsaw, Poland, pp. 161-171.

[11] A.E. Naaman, G.G. Namur, J.M. Alwan, H.S. Najm. 1991. Fiber Pullout and Bond Slip. II: Experimental Validation. Journal of Structural Engineering 117: 2791-2800.

[12] C.K.Y. Leung, N. Ybanez. 1997. Pullout of inclined flexible fiber in cementitious composite. Journal of Engineering Mechanics 123: 239-246.

[13] S. Singh, A. Shukla, R. Brown. 2004. Pullout behavior of polypropylene fibers from cementitious matrix. Cement and Concrete Research 34: 1919-1925.

[14] S.C. Lee, K.J. Shin, B.H. Oh. 2011. Cyclic pull-out test of single PVA fibers in cementitious matrix. Journal of Composite
Materials 45: 2765-2772.

[15] N. Banthia, J.F. Trottier. 1994. Concrete Reinforced with Deformed Steel Fibers, Part 1: Bond-Slip Mechanisms. ACI Materials Journal 91: 435-446.

[16] P. Robins, S. Austin, P. Jones. 2002. Pullout behaviour of hooked steel fibres. Materials and Structures 35: 434-442.

[17] V. Cunha, J. Barros, J. Sena-Cruz. 2010. Pullout Behavior of Steel Fibers in SelfCompacting Concrete. Journal of Materials in Civil Engineering 22: 1-9.

[18] E. Zīle, O. Zīle. 2013. Effect of the fiber geometry on the pullout response of mechanically deformed steel fibers. Cement and Concrete Research 44: 18-24.

[19] K. Georgiadi-Stefanidi, E. Mistakidis, D. Pantousa, M. Zygomalas. 2010. Numerical modelling of the pull-out of hooked steel fibres from high-strength cementitious matrix, supplemented by experimental results. Construction and Building Materials 24: 2489-2506.

[20] V.C. Li, Y. Wang, S. Backer. 1990. Effect of Inclining Angle, Bundling and Surface Treatment on Synthetic Fiber Pull-out from a Cement Matrix. Composites 21: 132-140.

[21] M. Maalej, V.C. Li, T. Hashida. 1995. Effect of Fiber Rupture on Tensile Properties of Short-Fiber Composites. Journal of Engineering Mechanics 121: 903-913.

[22] C.K.Y. Leung, J. Chi. 1995. CrackBridging Force in Random Ductile Fiber Brittle Matrix Composites. Journal of Engineering Mechanics 121: 1315-1324.

[23] A.P. Fantilli, P. Vallini. 2007. A cohesive interface model for the pullout of inclined steel fibers in cementitious matrixes. Journal of Advanced Concrete Technology 5: 247-258.

[24] F. Laranjeira, C. Molins, A. Aguado. 2010. Predicting the pullout response of inclined hooked steel fibers. Cement and Concrete Research 40: 1471-1487.

[25] T. Soetens, A. Van Gysel, S. Matthys, L. Taerwe. 2013. A semi-analytical model to predict the pull-out behaviour of inclined hooked-end steel fibres. Construction and Building Materials 43: 253-265. 
[26] A.E. Naaman, S.P. Shah. 1976. Pull-out mechanism in steel fibre reinforced concrete. Journal of the Structural Division 102: 1537-1548.

[27] P.J.M. Bartos, M. Duris. 1994. Inclined tensile strength of steel fibres in a cementbased composite. Composites 25: 945-952.

[28] C. Ouyang, A. Pacios, S.P. Shah. 1994. Pullout of Inclined Fibers from Cementitious Matrix. Journal of Engineering Mechanics 120: 2641-2659.

[29] Y. Lee, S.-T. Kang, J.-K. Kim. 2010. Pullout behavior of inclined steel fiber in an ultra-high strength cementitious matrix. Construction and Building Materials 24: 2030-2041.

[30] C.K.Y. Leung, V.C. Li. 1992. Effect of Fiber Inclination on Crack Bridging Stress in Brittle Fiber Reinforced Brittle Matrix Composites. Journal of the Mechanics and Physics of Solids 40: 1333-1362.

[31] C.K.Y. Leung, Y.P. Geng. 1995. Effect of Lateral Stresses on Fiber Debonding/PullOut. Composites Engineering 5: 1331-1348.

[32] J. Yu, C.K.Y. Leung. 2014. Strength Improvement of Strain-Hardening Cementitious Composites (SHCC) with Ultra-High Volumes of Fly Ash. in: E. Schlangen, et al. (Eds.) Proceedings of 3rd International RILEM Conference on Strain Hardening Cementitious Composites (SHCC3), RILEM Publications S.A.R.L, Dordrecht, the Netherlands, pp. 97-104.

[33] ASTM. 2012. Standard Practice for Making and Curing Concrete Test Specimens in the Field. C31/C31M, ASTM International, West Conshohocken, PA, USA.

[34] K. Asano, T. Kanakubo, T. Matsushima. 2010. Study on size effect in bending behavior of ECC. in: B.H. Oh, et al. (Eds.) Proceedings of 7th International Conference on Fracture Mechanics of Concrete and Concrete Structures (FraMCoS-7), Korea. 